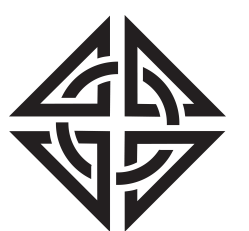

SCIENTIA

I RAN I C A
Sharif University of Technology

Scientia Iranica

Transactions F: Nanotechnology

www.scientiairanica.com

\title{
Enhanced electro-oxidation of urea based on nickel nanoparticle decorated reduced graphene oxide/PEDOT:PSS composite
}

\author{
M. Mazloum-Ardakani*, F. Farbod and L. Hosseinzadeh \\ Department of Chemistry, Faculty of Science, Yazd University, Yazd, P.O. Box 89195-741, Iran. \\ Received 21 June 2016; received in revised form 4 October 2016; accepted 28 January 2017
}

\author{
KEYWORDS \\ $\operatorname{Poly}(3,4-$ \\ ethylenedioxythiophene); \\ Reduced graphene \\ oxide; \\ Nickel nanoparticles; \\ Electro-oxidation; \\ Urea.
}

\begin{abstract}
A facile two-step systematic plan of action was used to prepare nanocomposite of Reduced Graphene Oxide (RGO) doped poly(3,4-ethylenedioxythiophene):poly (styrene sulfonate) (PEDOT:PSS) decorated with nickel nanoparticles (Ni NPs) onto a Glassy Carbon Electrode (GCE). Composites of PEDOT:PSS and RGO were prepared by mixing each component solution and were fabricated as a beneficial substrate for $\mathrm{Ni}$ NPs. Ni NPs were electrodeposited on the PEDOT-RGO support by applying constant potential into nickel ions solutions. Then, Ni/PEDOT-RGO/GCE was employed as an efficient electrocatalyst for electrooxidation of urea. The electrocatalytic properties of Ni NPs/PEDOT-RGO modified glassy carbon electrode toward the oxidation of urea were analyzed by Cyclic Voltammetry (CV) and chronoamperometry (CA). Such studies evidenced the high electrocatalytic activity of Ni NPs and mixed PEDOT-RGO, which is mainly ascribed to the good electrochemical activity of PEDOT-RGO composites and the well-dispersed Ni NPs on the surface of PEDOT-RGO composite.
\end{abstract}

(C) 2017 Sharif University of Technology. All rights reserved.

\section{Introduction}

To date, the development of clean power sources and the reduction of the emission of greenhouse gases (e.g., carbon dioxide) have led to many investigations into generation of pure hydrogen [1]. Urea is a major product of the metabolization of many nitrogen containing compounds in the human body $[2,3]$. Also, urea with 0.33 molar concentration in human urine is the major constituent of it, which results in large concentrations of urea in wastewater sewage systems $[4,5]$. Urea is not directly poison, but it can go through a natural conversion to ammonia, and

*. Corresponding author. Tel.: +98 3518211670 ; Fax: +983518210644

E-mail addresses: mazloum@yazd.ac.ir ( $M$.

Mazloum-Ardakani); farbodfatemeh@gmail.com (F. Farbod);

l.hosseinzadeh2011@gmail.com (L.Hosseinzadeh) then be released to the atmosphere. Ammonia in the atmosphere can be oxidized; therefore, it generates environmental pollutants, such as nitrate and nitric oxides. The ammonia can dissolve into the rain drops and form nitric acid. Ammonia poses risks to the soil and water and causes health problems [68]. Thus, treatment of urea has become as important environmental problems [9]. Various methods, such as chemical and biological decomposition and thermolysis, have been utilized for urea dissociation [10-12]. But, urea electrolysis has proven to be an effective technology to cure urea-rich wastewater with the simultaneous pure hydrogen generation [13-15]. Hence, urea can act as a stable, accessible, non-toxic, non-flammable, renewable and cheap hydrogen carrier [16,17]. However, an efficient catalyst for urea electro-oxidation is usually required to achieve high current densities at low overpotential.

Graphene (GR) is a monolayer of carbon atoms 
with $\mathrm{SP}^{2}$ hybrid that are fastened and pressed together into a two-dimensional, honeycomb solid formed structure [18]. GR-based materials possess superabundant unanticipated properties, such as extraordinary electronic transport properties, extent surface area, and strong mechanical strength [19], which have been investigated in electrochemical sensors, super capacitors, and fabricated field-effect transistors [20,21]. Another important category of novel materials for various electrochemical applications is Conductive Polymers (CPs). CPs have emerged as intelligent materials that can be applied for the development of various devices such as sensors due to their radically distinctive properties, such as high conductivity, light weight, and excellent processability $[22,23]$. In recent years, interest in the preparation of nanocomposites of conducting polymers and graphene has been put on notice intensively due to cooperating for enhanced effects resulting from the combination of these two classes of compounds [24-26]. Graphene-based polymer nanocomposite has exhibited several fold increases in electrical conductivity. The remarkable improvement in electrical conductivity is due to the formation of a conducting network by graphene sheets in the polymer matrix. In such a nanocomposite, the maximum electrical conductivity is obtained using a very low graphene loading in different polymer matrices compared to other carbon fillers [26].

Among various CPs, Poly(3,4-ethylenedioxythiophene): poly(styrene-sulfonate) (PEDOT:PSS) should be one of the best choices to incorporate into graphene due to its high electrical conductivity and extremely skillful stability compared to other CPs $[27,28]$. It is known that PEDOT has low-band gap, high environmental stability, and high optical transparency in the oxidized, conductive state [29]. Thus, combination of graphene and conductive polymers as catalyst support materials may increase catalytic activity of NPs. The excellent electric properties of graphene and the unique advantages of PEDOT have attracted great research interests in preparing graphene-PEDOT composites as support materials [30]. Therefore, the synthesis of hybrid materials consisting of graphene with PEDOT matrix as support materials for metal NPs catalysts is an interesting approach to improve the catalytic behavior of metal NPs, because this composite structure is a more conductive support material than other carbon materials and leads to the formation of mono dispersive metal NPs on the surface of the hybrid materials based on the strong coordination interaction between PEDOT and metal NPs $[30,31]$.

In this work, we used RGO-PEDOT nanocomposite as a substrate for Ni NPs effective immobilization. The Ni NPs were directly electrodeposited onto the support. Catalysts with different PEDOT composi- tions were investigated. The results demonstrate that $\mathrm{Ni} / \mathrm{PEDOT}-\mathrm{RGO} / \mathrm{GCE}$ with large active surface area exhibits great catalytic activity and good durability for urea oxidation.

\section{Experimental}

\subsection{Chemicals}

All solutions were freshly prepared with dionized water. Urea, PEDOT:PSS, graphite powder, $\mathrm{NH}_{3}, \mathrm{H}_{3} \mathrm{PO}_{4}$, $\mathrm{H}_{2} \mathrm{O}_{2}$, ethanol, $\mathrm{HCl}, \mathrm{KMnO}_{4}$, hydrazine $\left(\mathrm{N}_{2} \mathrm{H}_{4}, 98 \%\right)$, sulfuric acid, $\mathrm{Ni}\left(\mathrm{NO}_{3}\right), \mathrm{NaOH}$, and $\mathrm{CH}_{3} \mathrm{COOH}$ were purchased from Merck.

\subsection{Electrochemical measurements}

The electrochemical oxidation of urea performed in a conventional three-electrode cell was used at $25 \pm 1^{\circ} \mathrm{C}$. A saturated calomel electrode, a platinum wire, and a $\mathrm{Ni} / \mathrm{RGO}-\mathrm{PEDOT} / \mathrm{GCE}$ were used as a reference, an auxiliary, and working electrodes, respectively. The electrolyte for urea electro-oxidation was dissolved in $1 \mathrm{M} \mathrm{NaOH}$ aqueous solution. Electrochemical experiments were performed using a computerized potentiostat/galvanostat (SAMA 500, electroanalyzer, system, I.R. Iran).

\subsection{Preparation of the PEDOT-RGO composite}

For this purpose, firstly, Graphene Oxide (GO) was obtained by oxidizing graphite using an improved method [32]. In brief, a 9:1 mixture of concentrated $\mathrm{H}_{2} \mathrm{SO}_{4} / \mathrm{H}_{3} \mathrm{PO}_{4}(360: 40 \mathrm{~mL})$ was added to a mixture of graphite flakes $(3.0 \mathrm{~g})$ and $\mathrm{KMnO}_{4}(18.0 \mathrm{~g})$. The reaction was then heated to $\sim 50^{\circ} \mathrm{C}$ and stirred for $12 \mathrm{~h}$. Then, the reaction pot was cooled to room temperature and poured onto deionized ice $(400 \mathrm{~mL})$ with $30 \% \quad \mathrm{H}_{2} \mathrm{O}_{2}(3 \mathrm{~mL})$. The obtained solution was filtered. The solid material was then washed with water until $\mathrm{pH}$ became neutral, and subsequently washed with $30 \% \mathrm{HCl}$, and finally twice with $200 \mathrm{~mL}$ of ethanol. The solid obtained on the filter was vacuumdried for $24 \mathrm{~h}$ at $40^{\circ} \mathrm{C}$ [20]. The graphite oxide was obtained as a light brown powder. Reduced graphene oxide was produced using hydrazine together with ammonia solution. A colloidal suspension of GO in purified water $(100 \mathrm{mg} / 100 \mathrm{~mL})$ was prepared by sonication for $2 \mathrm{~h}$. Subsequently, $150 \mu \mathrm{L}$ of hydrazine solution (98\%) was added. Then, it was refluxed at $80^{\circ} \mathrm{C}$ for $12 \mathrm{~h}$ in a heating mantle and cooled down to room temperature. Finally, solutions were centrifuged, and RGO precipitates were washed with distilled water, and then dried at $60^{\circ} \mathrm{C}$ in vacuum for $12 \mathrm{~h}$. Then, in a simple procedure, $2 \mathrm{mg}$ of RGO powder was added into $1 \mathrm{~mL}$ dionized water for the synthesis of PEDOT-RGO composites, followed by sonication for $30 \mathrm{~min}$. Then, the above solution was added into $1 \mathrm{~mL}$ PEDOT:PSS solution in deionized 
water $(1 \% \mathrm{~W} / \mathrm{W})$ and followed by sonication for 30 $\min$.

\subsection{Preparation of Ni/RGO-PEDOT/GC electrode}

Modified electrodes were prepared by a simple casting method. Prior to the surface coating, Glassy Carbon (GC) electrode polished with alumina was used as substrates for the supported catalysts. The PEDOTRGO mixture was treated for 30 min with ultrasonication for uniform dispersion. A volume $(2 \mu \mathrm{L})$ of this mixture was dropped by a microsampler onto the top surface of the GC electrode and dried under room temperature. Then, the as-prepared modified electrodes were treated with nickel ions solution. Nickel NPs were electrodeposited onto the surface of PEDOTRGO/GCE from $5 \mathrm{mM}$ nickel nitrate solution, applying constant potential at $-1.1 \mathrm{~V}$ for $12 \mathrm{sec}$ using chronoamperometry method. Modified electrode was eventually washed with double distilled water in order to remove the electrolytes, large and agglomerated NPs. The asobtained catalyst-modified GC electrode was employed as the working electrode in our experiments.

In order to gain the best conditions in the preparation of the Ni/PEDOT-RGO/GCE for catalyst performance, we optimized the concentration and volume of RGO suspensions, PEDOT solution volume, and electrodeposition time of nickel nanoparticles. For comparison, PEDOT-RGO/GCE without $\mathrm{Ni}$, Ni/PEDOT modified without RGO, and unmodified GCE were also prepared in the same way.

\section{Results and discussion}

\subsection{Morphologies of Ni/PEDOT-RGO nanocomposites}

The morphologies of Ni/RGO and Ni/PEDOT-RGO composites were investigated by Scanning Electron Microscopy (SEM). In Ni-RGO composite, Ni NPs were speard on the graphene nanosheets (Figure 1(a)), with the average particle size being equal to $50 \mathrm{~nm}$. On the other hand, Ni/PEDOT-RGO composite has a homogeneous sheet-like structure with granular PEDOT distributed on the RGO surfaces, and Ni nanoparticles deposited on PEDOT-RGO support were observable (Figure 1(b)). This image clearly shows RGO, PEDOT, and Ni NPs that resulted in the formation of a nanocomposite film. When PEDOT was introduced into Ni/RGO nanocomposite, the film becomes more uniform and even, most likely due to the binding and blanketing effects of polymer.

The weight of deposited $\mathrm{Ni}$ nanoparticles can be evaluated from chronoamperometry experiments by using the total mols of electrons, according to the Faraday's law. The evaluated value for the weight of deposited Ni nanoparticles is $1 \times 10^{-7}$ gr.

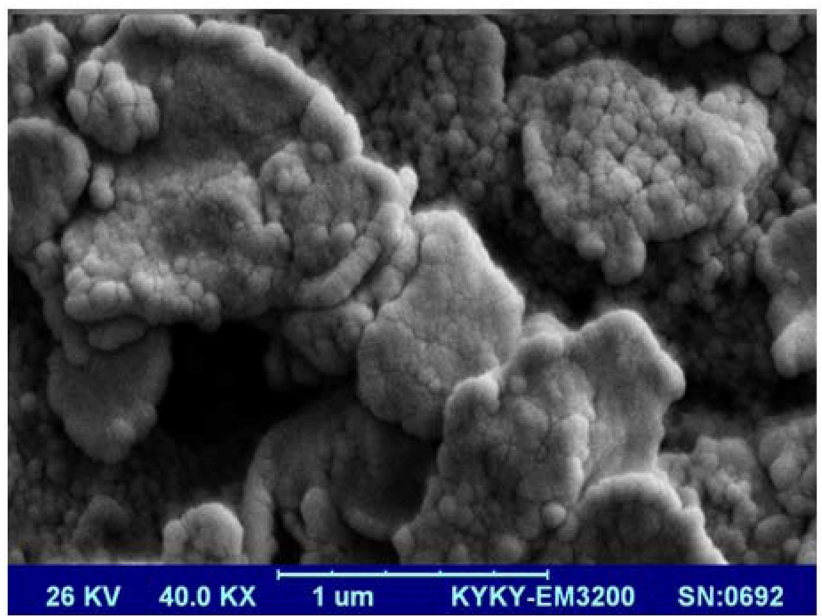

(a)

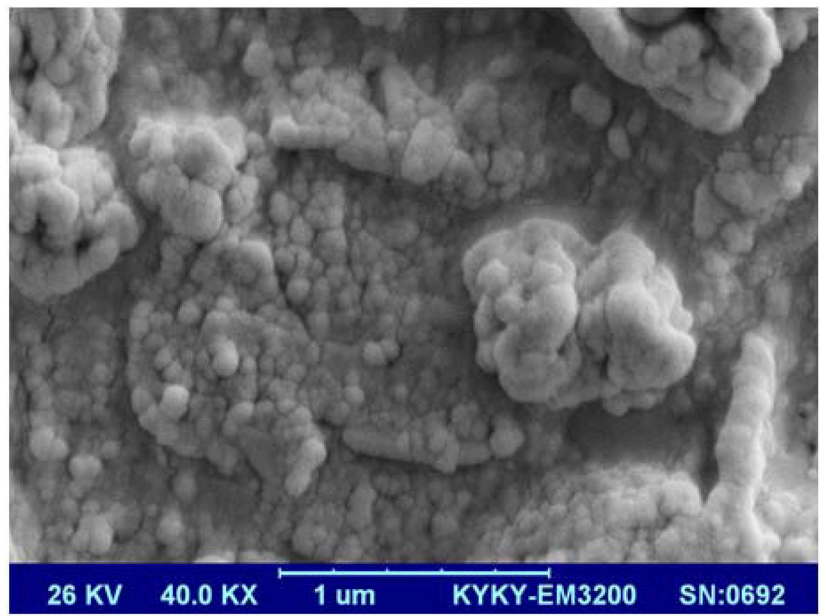

(b)

Figure 1. SEM images of (a) Ni/RGO and (b) Ni/ PEDOT-RGO.

\subsection{Electrochemical behavior of Ni/PEDOT-RGO/GCE}

It is well known that $\mathrm{Fe}(\mathrm{CN})_{6}^{3-/ 4-}$ redox couple can be used as a proof to characterize the electron transfer properties of the electrodes. Figure 2 shows the electrochemical behavior of electrodes in $5.0 \mathrm{mM} \mathrm{Fe}(\mathrm{CN})_{6}^{3-/ 4-}$ solution containing $0.1 \mathrm{M}$ $\mathrm{KCl}$. Typical $\mathrm{CVs}$ of $\mathrm{Fe}(\mathrm{CN})_{6}^{3-/ 4-}$ at bare $\mathrm{GCE}$, $\mathrm{Ni} / \mathrm{RGO} / \mathrm{GCE}$, PEDOT-RGO/GCE, and Ni/PEDOT$\mathrm{RGO} / \mathrm{GCE}$ with a scan rate of $40 \mathrm{mVs}^{-1}$ were used to evaluate the electron transfer ability of the modified GCE as a redox probe. It can be seen that Ni/PEDOT-RGO/GCE showed higher oxidation peak current $(51 \mu \mathrm{A})$ than that of the bare GCE $(16 \mu \mathrm{A}), \mathrm{Ni} / \mathrm{RGO} / \mathrm{GCE}(30 \mu \mathrm{A})$, and PEDOT$\mathrm{RGO} / \mathrm{GCE}(38 \mu \mathrm{A})$. This result indicated that the RGO and PEDOT facilitated the electron transfer. DPV was used for further characterization of the modified electrode. Inset of Figure 2 demonstrates DPVs of various electrodes in $5.0 \mathrm{mM} \mathrm{Fe}(\mathrm{CN})_{6}^{3-/ 4-}$ 


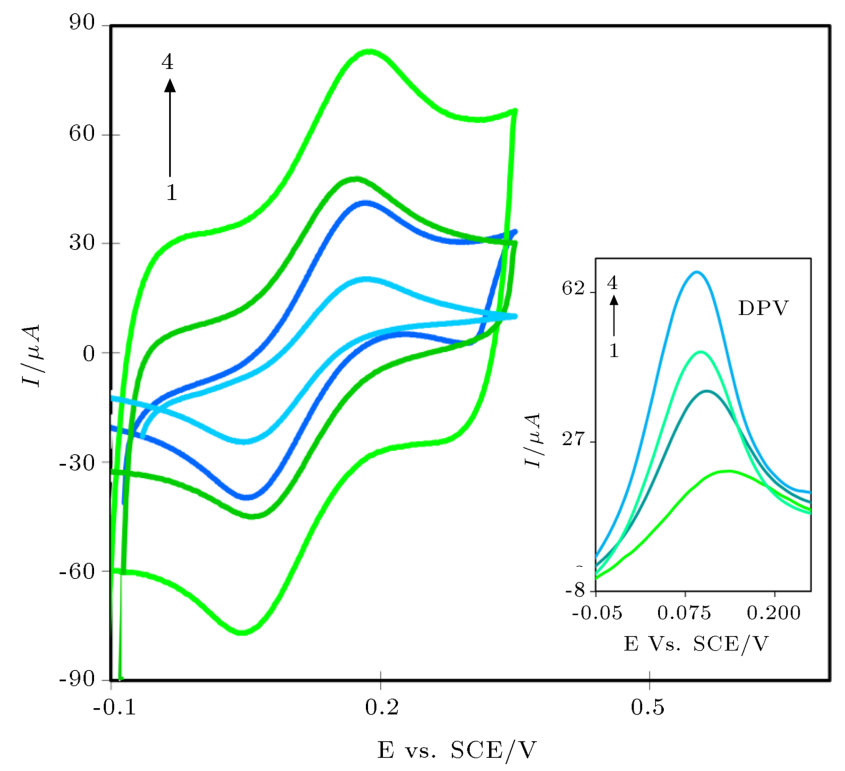

Figure 2. Cyclic voltammograms of bare GC, $\mathrm{Ni} / \mathrm{RGO} / \mathrm{GC}$, PEDOT-RGO, and Ni/PEDOT-RGO/GC electrodes in the electrolyte solution containing $5.0 \mathrm{mM}$ $\mathrm{Fe}(\mathrm{CN})_{6}^{3-/ 4-}$ and $0.1 \mathrm{M} \mathrm{KCl}$. Scan rate: $40 \mathrm{mVs}^{-1}$, Inset: DPV for various electrodes.

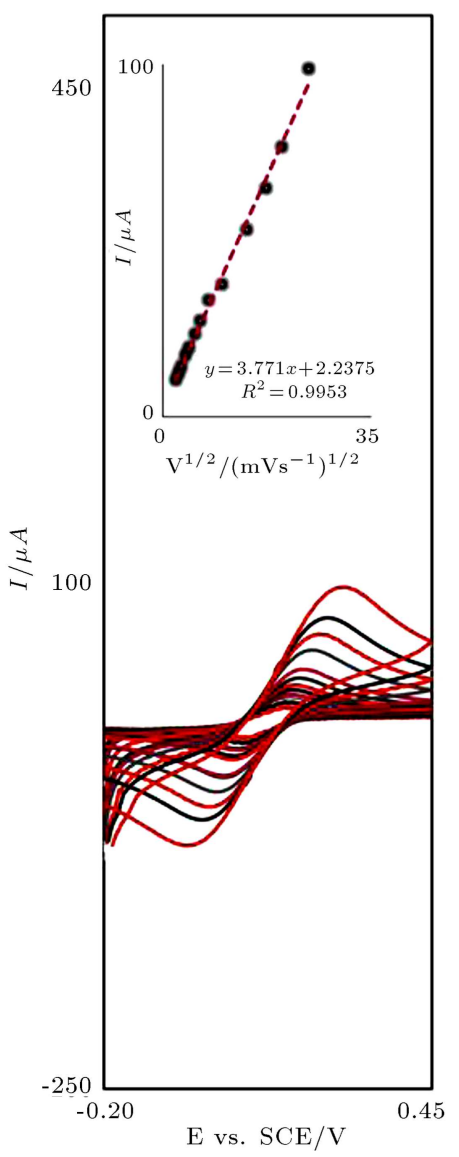

(a)

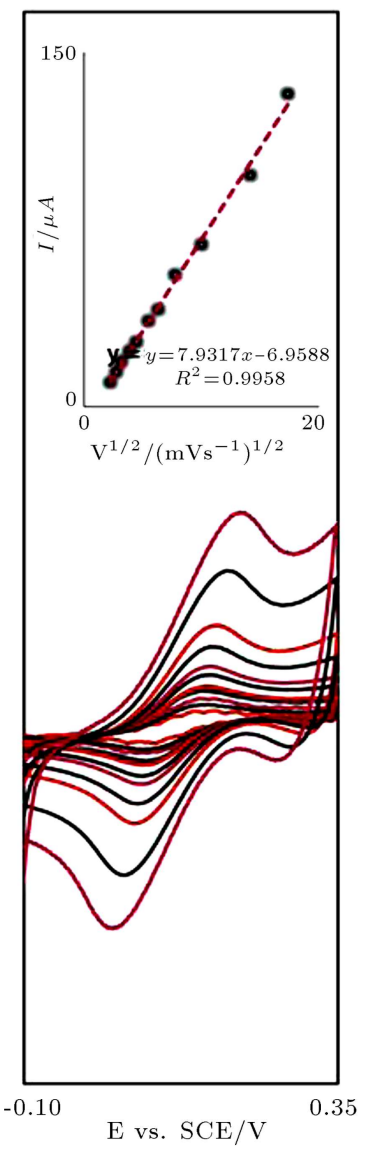

(b) solution containing $0.1 \mathrm{M} \mathrm{KCl}$. It was observed that the Ni/PEDOT-RGO/GCE electrode produces a higher peak current in comparison with that of the other electrode. This could be attributed to the higher electrochemically active surface area of the Ni/PEDOT$\mathrm{RGO} / \mathrm{GCE}$ which is in agreement with the results of cyclic voltammetry [33].

Figure 3 displays a series of cyclic voltammograms on the modified electrodes in different scan rates and the dependence of the peak current $\left(I_{p}\right)$ on the square root of the scan rate $\left(\nu^{1 / 2}\right)$ for the demonstrated electrodes (insets of Figure 3 ) in $5.0 \mathrm{mM} \mathrm{Fe}(\mathrm{CN})_{6}^{3-/ 4-}$ solution containing $0.1 \mathrm{M} \mathrm{KCl}$. A, B, C, and D corresponded to the bare GCE, Ni/PEDOT/GCE, RGO$\mathrm{PEDOT} / \mathrm{GCE}$, and Ni/RGO-PEDOT/GCE, respectively. As can be observed in Figure 3, the oxidation peak potential shifted to more positive potentials with increasing scan rate, confirming the kinetic limitation on the electrochemical reaction; moreover, the anodic and cathodic peaks of electrodes were found to move into opposite directions, suggesting the redox process to be quasi-reversible [34]. Also, the linearity of $I_{p}$ versus $\nu^{1 / 2}$ indicates that the electrochemical reaction

Figure 3. Cyclic voltammograms: (a) bare GCE, (b) Ni/RGO/GCE, (c) RGO-PEDOT/GCE, and (d)

$\mathrm{Ni} /$ RGO-PEDOT/GCE in different scan rates. Insets show the plot of the anodic current vs. the square root of the scan rate. Electrolyte solution: $5 \mathrm{mM} \mathrm{Fe}(\mathrm{CN})_{6}^{3-/ 4-}$ and $0.1 \mathrm{M} \mathrm{KCl}$.

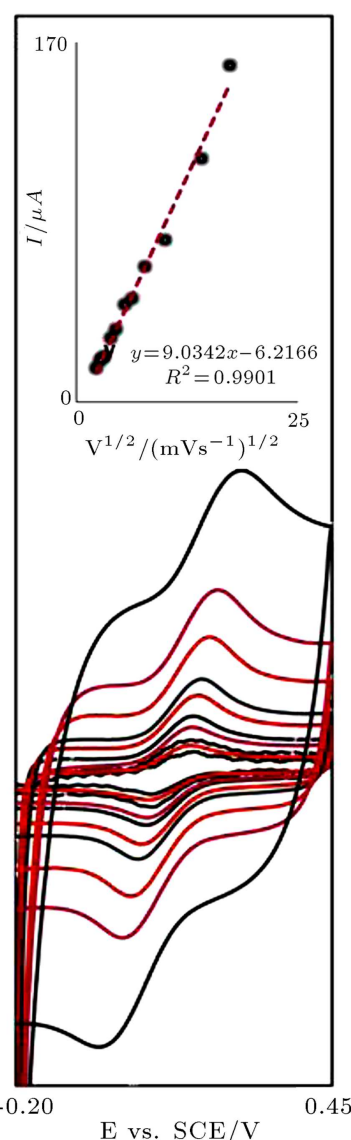

(c)

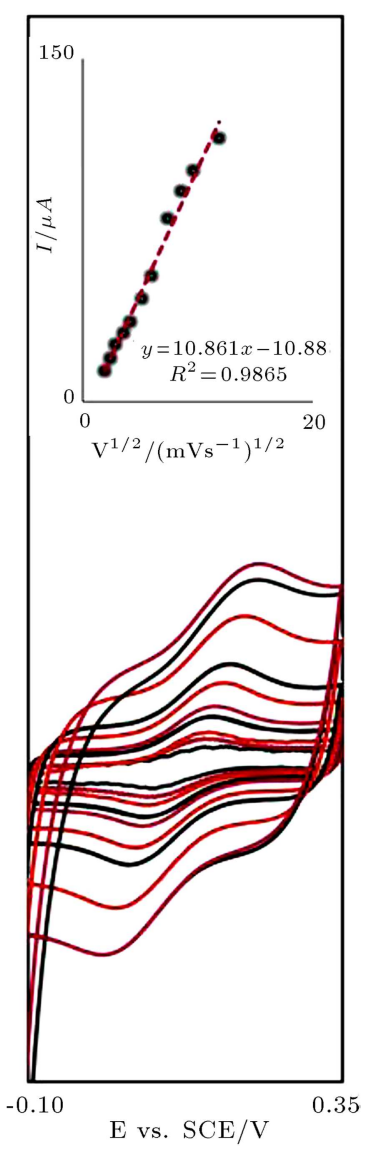

(d) 
is controlled by semi-infinite linear diffusion from the electrolyte to the electrode surface [34].

The electrochemical active surface areas of four modes of electrode, including the Ni/RGOPEDOT/GCE, Ni/RGO/GCE, PEDOT-RGO/GCE, and bare GCE, were calculated by cyclic voltammetry using $5.0 \mathrm{mM}\left[\mathrm{Fe}(\mathrm{CN})_{6}\right]^{3-/ 4-}$ redox probe prepared in $0.1 \mathrm{M} \mathrm{KCl}$. The electrochemically active surface area can estimate the access of a conductive path available to transfer electrons to and from the electrode surface and also assign the number of catalytically active sites available to an electrochemical reaction $[35,36]$.

Based on the slopes of the curves of $I_{p}$ versus $\nu^{1 / 2}$ and by using Randles-Sevcik equation, for Ni/RGOPEDOT/GCE, RGO-PEDOT/GCE Ni/RGO/GCE, and bare GCE, active surface areas were calculated as $0.098,0.081,0.071$, and $0.03 \mathrm{~cm}^{2}$, respectively.

The comparison of the active surface area of different electrodes shows an enhancement $(2.3,2.7$, and 3.3 times for Ni/RGO/GCE, RGO-PEDOT/GCE, and $\mathrm{Ni} / \mathrm{RGO}-\mathrm{PEDOT} / \mathrm{GCE}$, respectively, compared to the bare GCE), which indicates that the presence of RGO nanosheet can enhance the active surface area of electrode. The advantages of Ni/PEDOT-RGO/GCE were elucidated with higher conductivity, fast electron transfer rate, good anti-agglomerate properties, and inherent catalytic ability of RGO and PEDOT [24-26].

\subsection{Electrocatalytic oxidation of urea at $\mathrm{Ni} / \mathrm{RGO-PEDOT/GCE}$}

Prior to evaluation of the electrocatalytic activity of the as-prepared catalysts toward urea oxidation, one cycle of potential sweeps between $0 \mathrm{~V}$ and $0.9 \mathrm{~V}$ at $100 \mathrm{mVs}^{-1}$ was applied onto the GC electrode modified with catalysts in $1 \mathrm{M}$ sodium hydroxide solution in the absence of urea. As shown in Figure 4, for the Ni/PEDOT-RGO/GCE, Ni/PEDOT /GCE, PEDOT/GCE, PEDOT-RGO/GCE, and RGO/GCE,

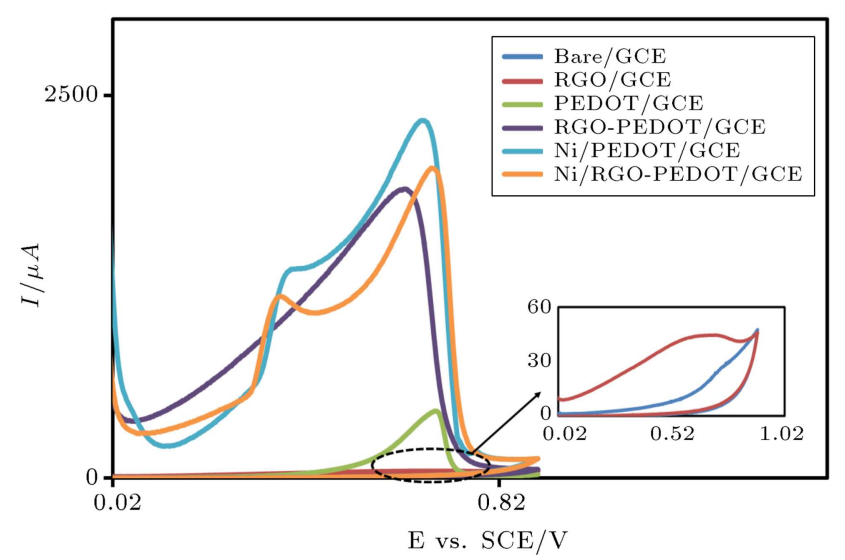

Figure 4. CVs of Ni/PEDOT-RGO/GCE,

$\mathrm{Ni} / \mathrm{PEDOT} / \mathrm{GCE}, \mathrm{PEDOT} / \mathrm{GCE}, \mathrm{PEDOT}-\mathrm{RGO} / \mathrm{GCE}$, and $\mathrm{RGO} / \mathrm{GCE}$ in $1.0 \mathrm{M} \mathrm{NaOH}$ solution at the scan rate of $100 \mathrm{mVs}^{-1}$.

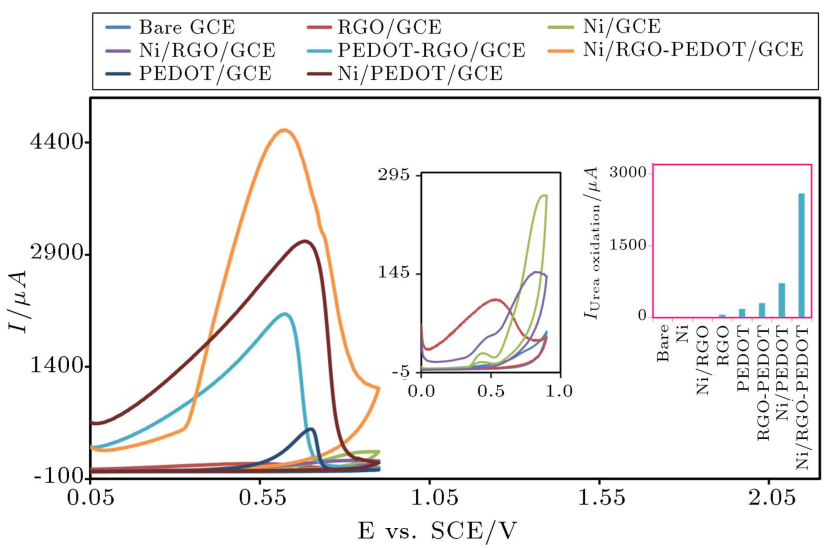

Figure 5. CVs for bare GCE, RGO/GCE, Ni/GCE, PEDOT/GCE, PEDOT-RGO/GCE, Ni/PEDOT/GCE, and Ni/PEDOT-RGO/GCE in $0.3 \mathrm{M}$ urea and $1.0 \mathrm{M}$ $\mathrm{NaOH}$ solution at a scan rate of $100 \mathrm{mV} \mathrm{s}^{-1}$.

an oxidation peak was observed that can be attributed to the over-oxidation reaction onto the surface of $\mathrm{PE}$ DOT [37]. Another peak for Ni/PEDOT-RGO/GCE was also detected in $0.4 \mathrm{~V}$ ascribed as nickel nanoparticles oxidation [38].

Figure 5 shows the cyclic voltammograms for bare, RGO, Ni, PEDOT, PEDOT-RGO, Ni/PEDOT/ GCE, and Ni/PEDOT-RGO GCE as different catalystcoated electrodes in $0.3 \mathrm{M}$ urea and $1 \mathrm{M} \mathrm{NaOH}$ solution at a scan rate of $100 \mathrm{mV} \mathrm{s}^{-1}$. The highest peak currents were observed on Ni/PEDOT-RGO/GCE, indicating the highest catalytic activity for urea oxidation, nearly 6, 2.4, and 1.5 times that on PEDOT/GCE, PEDOTRGO/GCE, and Ni/PEDOT/GCE electrode catalysts, respectively, indicating that $\mathrm{Ni} / \mathrm{PEDOT}-\mathrm{RGO} / \mathrm{GCE}$ might provide much more electroactive sites than other modified electrodes for urea. The synergistic effect could also be observed in this case. As shown in Figure 5, there were no obvious oxidation peaks on the bare GCE, indicating that the bare electrode unfit to urea oxidation and the electrocatalytic performance of bare GCE can be neglected in the presence of urea. To investigate the role of PEDOT on RGO surface in the electrochemical oxidation of urea, the cyclic response of the RGO/GC and PEDOT-RGO/GC electrodes was also recorded. The results indicated that the presence of PEDOT on graphene matrix exhibited 6 times improvement on the oxidation peak current for urea at PEDOT-RGO composite. The higher electrocatalytic current response of the PEDOT-RGO composite than that of the RGO film was presumably caused by a more favorable electrochemical environment for urea on the electrode [39]. PEDOT:PSS chains can be assembled onto the surfaces of RGO sheets through $\pi$ stacking interactions between both components $[40,41]$. The close interaction between PEDOT and RGO in the PEDOT-RGO composite allows the PEDOT to accumulate more electrons in PEDOT-RGO composite 
than in RGO without PEDOT. Moreover, due to the nanometer size, large accessible surface per volume, high conductivity, and well dispersion, the PEDOTRGO nanocomposite offers a favorite microenvironment for electron transfer between urea and the underlying electrode, which results in the improvement on the electrochemical response [42].

The urea electrochemical decomposition process in alkaline media is described below:

$$
\begin{aligned}
& \mathrm{CO}\left(\mathrm{NH}_{2}\right)_{2}(\mathrm{aq})+6 \mathrm{OH}^{-} \rightarrow \mathrm{N}_{2}(\mathrm{~g})+5 \mathrm{H}_{2} \mathrm{O}(\mathrm{l}) \\
& +\mathrm{CO}_{2}(\mathrm{~g})+6 \mathrm{e}^{-}
\end{aligned}
$$

Hence, Ni NPs/PEDOT-RGO catalyst is promising material for urea removal or decomposition from urearich wastewater.

The results indicated that the presence of RGO in the polymer matrix surface had great improvement on the electrochemical response (an enhancement of the peak current). The superior performance of $\mathrm{Ni} / \mathrm{PEDOT}-\mathrm{RGO} / \mathrm{GCE}$ catalysts may arise from utilization of heterogeneous nucleation sites for NPs and the greatly increased electronic conductivity of the supports.

The steady-state behavior of urea oxidation on the surface of nanocomposite was studied by chronoamperometric measurement. Figure 6 indicates the results of chronoamperometric measurements of bare GCE (a), Ni/GCE (b), RGO/GCE (c), PEDOT-RGO/GCE (d), $\mathrm{Ni} / \mathrm{PEDOT}-\mathrm{RGO} / \mathrm{GCE}$ (e) electrodes in the presence of urea. All electrodes reach a steady-state Faradic current response within $15 \mathrm{sec}$ approximately. It was observed that Ni/PEDOT-RGO/GCE electrode produces a higher steady-state current density in comparison with that of the other electrode during the whole measurements. This could be attributed to the higher electrochemically active surface area of Ni/PEDOTRGO/GCE which is in agreement with the results of cyclic voltammetry of urea oxidation.

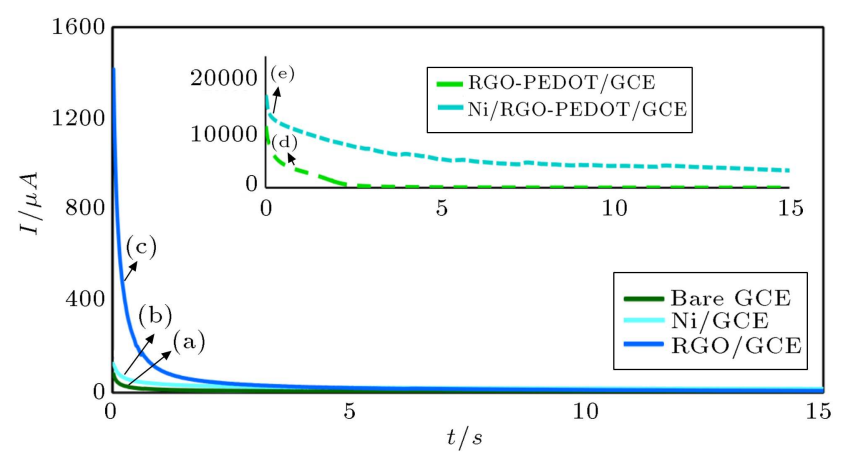

Figure 6. Chronoamperograms of bare GCE (a), Ni/GCE (b), RGO/GCE (c), PEDOT-RGO/GCE (d), and $\mathrm{Ni} / \mathrm{PEDOT}-\mathrm{RGO} / \mathrm{GCE}$ (e) electrodes in the presence of $0.3 \mathrm{M}$ urea and $1 \mathrm{M} \mathrm{NaOH}$ at constant potential of $0.7 \mathrm{~V}$.

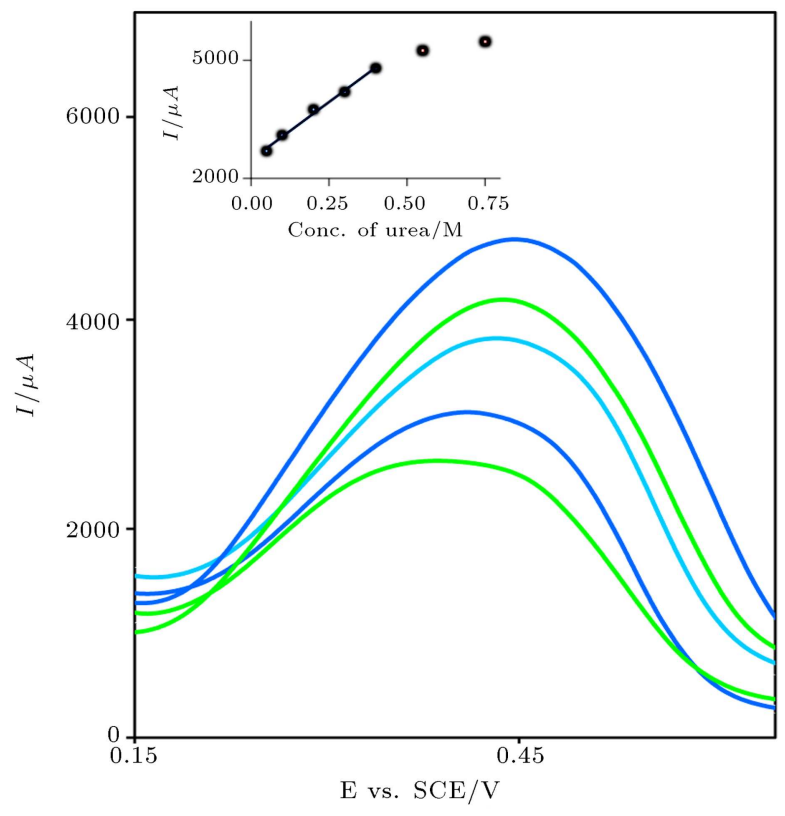

Figure 7. Linear sweep voltammograms of solutions containing $0.05,0.1,0.2,0.3,0.55,0.65$, and 0.75 ureas in $1 \mathrm{M} \mathrm{NaOH}$.

Figure 7 shows the effect of urea concentration on the anodic peak current at Ni/PEDOT-RGO/GCE in $1 \mathrm{M} \mathrm{NaOH}$. It is clearly observed that as the urea concentration increases, the peak height increases linearly with urea concentration up to $0.40 \mathrm{M}$. It could be assumed that the increase is due to the presence of a diffusion controlled process that appears to play an important role at low urea concentrations. While the urea concentration exceeds this limit, the rate of the whole oxidation process seems to be limited by that of the catalytic process in origin and its rate depends on the reaction among urea and composite species.

\section{Conclusion}

Nanocomposite of Ni/RGO-PEDOT:PSS was prepared by a facile two-step method; first, mixing solution of RGO and PEDOT:PSS was performed, and then $\mathrm{Ni}$ NPs were electrodeposited on the composite film through electrochemical deposition. Electrochemical studies, such as cyclic voltammetry and chronoamperometry, were performed. Owing to the synergistic effect of PEDOT-RGO and Ni NPs, Ni NPs/PEDOTRGO modified electrode exhibited excellent electrocatalytic activity toward urea oxidation, and it could be developed into a highly desirable urea decomposer and hydrogen producer.

\section{Acknowledgements}

The authors wish to thank the Yazd University Research Council, the IUT Research Council and Excellence in Sensors for financial support of this research. 


\section{References}

1. Lamy, C., Jaubert, T., Baranton, S. and Coutanceau, C. "Clean hydrogen generation through the electrocatalytic oxidation of ethanol in a Proton Exchange Membrane Electrolysis Cell (PEMEC): Effect of the nature and structure of the catalytic anode", J. Power Sources, 245, pp. 927-936 (2014).

2. Bello, A., Fabiane, M., Dodoo-Arhin, D., Ozoemena, K.I. and Manyala, N. "Silver nanoparticles decorated on a three-dimensional graphene scaffold for electrochemical applications", J. Phys. Chem. Solids, 75, pp. 109-114 (2014).

3. Shukla, S.K., Mishra, A.K., Mamba, B.B. and Arotiba, O.A. "Zirconia-poly (propylene imine) dendrimer nanocomposite based electrochemical urea biosensor", Enzyme Microb. Technol., 66, pp. 48-55 (2014).

4. Boggs, B.K., King, R.L. and Botte, G.G. "Urea electrolysis: direct hydrogen production from urine", Chem. Commun., 32, pp. 4859-4861 (2009).

5. Kojima, S., Bohner, A. and Von Wirén, N. "Molecular mechanisms of urea transport in plants", J. Membr. Biol., 212, pp. 83-91 (2006).

6. Yan, W., Wang, D. and Botte, G.G. "Nickel and cobalt bimetallic hydroxide catalysts for urea electrooxidation", Electrochim. Acta, 61, pp. 25-30 (2012).

7. King, R.L. and Botte, G.G. "Hydrogen production via urea electrolysis using a gel electrolyte", J. Power Sources, 196, pp. 2773-2778 (2011).

8. Simka, W., Piotrowski, J. and Nawrat, G. "Influence of anode material on electrochemical decomposition of urea", Electrochim. Acta, 52, pp. 5696-5703 (2007).

9. Yan, W., Wang, D. and Botte, G.G. "Electrochemical decomposition of urea with Ni-based catalysts", Appl. Catal. B Environ., 127, pp. 221-226 (2012).

10. Estiu, G. and Merz, K.M. "Enzymatic catalysis of urea decomposition: elimination or hydrolysis?", J. Am. Chem. Soc., 126, pp. 11832-11842 (2004).

11. Rahimpour, M.R. "A non-ideal rate-based model for industrial urea thermal hydrolyser", Chem. Eng. Process. Process Intensif., 43, pp. 1299-1307 (2004).

12. Gupta, S.K. and Sharma, R. "Biological oxidation of high strength nitrogenous wastewater", Water Res., 30, pp. 593-600 (1996).

13. Hernlem, B.J. "Electrolytic destruction of urea in dilute chloride solution using DSA electrodes in a recycled batch cell", Water Res., 39, pp. 2245-2252 (2005).

14. Jara, C.C., Di Giulio, S., Fino, D. and Spinelli, P. "Combined direct and indirect electroxidation of urea containing water", J. Appl. Electrochem., 38, pp. 915922 (2008).

15. Barakat, N.A.M., El-Newehy, M.H., Yasin, A.S., Ghouri, Z.K. and Al-Deyab, S.S. "Ni: Mn nanoparticles-decorated carbon nanofibers as effective electrocatalyst for urea oxidation", Appl. Catal. A Gen., 510, pp. $180-188$ (2016).
16. Liang, Y., Liu, Q., Asiri, A.M. and Sun, X. "Enhanced electrooxidation of urea using $\mathrm{NiMoO}_{4} \bullet \mathrm{xH}_{2} \mathrm{O}$ nanosheet arrays on $\mathrm{Ni}$ foam as anode", Electrochim. Acta, 153, pp. 456-460 (2015).

17. Ji, R.-Y., Chan, D.-S., Jow, J.-J. and Wu, M.-S. "Formation of open-ended nickel hydroxide nanotubes on three-dimensional nickel framework for enhanced urea electrolysis", Electrochem. Commun., 29, pp. 2124 (2013).

18. Zhao, N., Cheng, X.-N., Yang, J., et al. "Experimental study on the preparation, characterization and conductivity improvement of reduced graphene-oxide papers", J. Phys. Chem. Solids, 75, pp. 1141-1146 (2014).

19. Stoller, M.D., Park, S., Zhu, Y., An, J. and Ruoff, R.S. "Graphene-based ultracapacitors", Nano Lett., 8, pp. 3498-3502 (2008).

20. Mazloum-Ardakani, M., Khoshroo, A. and Hosseinzadeh, L. "Application of graphene to modified ionic liquid graphite composite and its enhanced electrochemical catalysis properties for levodopa oxidation", Sensors Actuators B Chem., 204, pp. 282-288 (2014).

21. Koohi, M.Z. and Neshat, M. "Evaluation of graphenebased terahertz photoconductive antennas", Sci. Iran. Trans. F, Nanotechnol., 22, pp. 1299-1305 (2015).

22. Mazloum-Ardakani, M., Sheikh-Mohseni, M.A. and Benvidi, A. "Electropolymerization of thin film conducting polymer and its application for simultaneous determination of ascorbic acid, dopamine and uric acid", Electroanalysis, 23, pp. 2822-2831 (2011).

23. Kiani, G., Mahmoudi, M. and Ghafari, A.S. "Electrical and electrochemical properties of the expanded graphite filled polythiophene nanocomposites", Sci. Iran. Trans. C, Chem. Chem. Eng., 22, p. 2290 (2015).

24. Gómez, H., Ram, M.K., Alvi, F., et al. "Grapheneconducting polymer nanocomposite as novel electrode for supercapacitors", J. Power Sources, 196, pp. 41024108 (2011).

25. Feng, X., Gan, N., Zhang, H., et al. "A novel strategy for multiplexed immunoassay of tumor markers based on electrochemiluminescence coupled with cyclic voltammetry using graphene-polymer nanotags", Electrochim. Acta, 170, pp. 292-299 (2015).

26. Kuilla, T., Bhadra, S., Yao, D.H., et al. "Recent advances in graphene based polymer composites", Prog. Polym. Sci., 35, pp. 1350-1375 (2010).

27. Antiohos, D., Folkes, G., Sherrell, P., et al. "Compositional effects of PEDOT-PSS/single walled carbon nanotube films on supercapacitor device performance", J. Mater. Chem., 21, pp. 15987-15994 (2011).

28. Wang, Z., et al. "Facile preparation of highly waterstable and flexible PEDOT: PSS organic/inorganic composite materials and their application in electrochemical sensors", Sensors Actuators B Chem., 196, pp. 357-369 (2014).

29. Park, S., Kwon, O., Lee, J., Jang, J. and Yoon, H. "Conducting polymer-based nanohybrid transducers: A potential route to high sensitivity and selectivity sensors", Sensors, 14, pp. 3604-3630 (2014). 
30. Yang, S., Shen, C., Liang, Y., et al. "Graphene nanosheets-polypyrrole hybrid material as a highly active catalyst support for formic acid electro-oxidation", Nanoscale, 3, pp. 3277-3284 (2011).

31. Motlak, M. Barakat, N.A.M., El-Deen, A.G., et al. " $\mathrm{NiCu}$ bimetallic nanoparticle-decorated graphene as novel and cost-effective counter electrode for dyesensitized solar cells and electrocatalyst for methanol oxidation", Appl. Catal. A Gen., 501, pp. 41-47 (2015).

32. Marcano, D.C., Kosynkin, D.V., Berlin, J.M., et al. "Improved synthesis of graphene oxide", ACS Nano, 4, pp. 4806-4814 (2010).

33. Chen, L., Tang, Y., Wang, K., Liu, C. and Luo, S. "Direct electrodeposition of reduced graphene oxide on glassy carbon electrode and its electrochemical application", Electrochem. Commun., 13, pp. 133-137 (2011).

34. Bard, A.J. and Faulkner, L.R., Electrochemical Methods: Fundamentals and Applications, 2, Wiley, New York (1980).

35. Li, S., Yang, H., Dong, Z., et al. "The role of reducing agent in perylene tetracarboxylic acid coating on graphene sheets enhances Pd nanoparticleselectrocalytic ethanol oxidation", Catal. Sci. Technol., 3, pp. 2303-2310 (2013).

36. Sharma, S., Ganguly, A., Papakonstantinou, P., et al. "Rapid microwave synthesis of $\mathrm{CO}$ tolerant reduced graphene oxide-supported platinum electrocatalysts for oxidation of methanol", J. Phys. Chem. C, 114, pp. 19459-19466 (2010).

37. Tehrani, P., Kanciurzewska, A., Crispin, X., et al. "The effect of $\mathrm{pH}$ on the electrochemical over-oxidation in PEDOT: PSS films", Solid State Ionics, 177, pp. 3521-3527 (2007).

38. Noorbakhsh, A. and Salimi, A. "Development of DNA electrochemical biosensor based on immobilization of ssDNA on the surface of nickel oxide nanoparticles modified glassy carbon electrode", Biosens. Bioelectron., 30, pp. 188-196 (2011).
39. Su, D.S., Perathoner, S. and Centi, G. "Nanocarbons for the development of advanced catalysts", Chem. Rev., 113, pp. 5782-5816 (2013).

40. Hong, W., Xu, Y., Lu, G., Li, C. and Shi, G. "Transparent graphene/PEDOT-PSS composite films as counter electrodes of dye-sensitized solar cells", Electrochem. Commun., 10, pp. 1555-1558 (2008).

41. Kim, G.H., Hwang, D.H. and Woo, S.I. "Thermoelectric properties of nanocomposite thin films prepared with poly (3, 4-ethylenedioxythiophene) poly (styrenesulfonate) and graphene", Phys. Chem. Chem. Phys., 14, pp. 3530-3536 (2012).

42. Mazloum-Ardakani, M. and Khoshroo, A. "Synthesis of $\mathrm{TiO}_{2}$ nanoparticle and its application to graphite composite electrode for hydroxylamine oxidation", $J$. Nanostructures, 3, pp. 269-275 (2013).

\section{Biographies}

Mohammad Mazloum-Ardakani received BSc in Chemistry from University of Kashan, Kashan, Iran, in 1986, MSc in Analytical Chemistry from Teacher Training University, Tehran, Iran, in 1990, and his $\mathrm{PhD}$ in Analytical Chemistry from Isfahan University, Isfahan, Iran, in 2000. He is Professor of Analytical Chemistry at the Chemistry Department in Yazd University, Yazd, Iran. His main areas of interest are electroanalytical chemistry and nanoelectrochemistry.

Fatemeh Farbod received her BSc in Chemistry and MSc in Analytical Chemistry from Yazd University, Yazd, Iran, in, respectively, 2012 and 2014. Since 2016, she is a PhD student in Analytical Chemistry at the same university.

Laleh Hosseinzadeh received her BSc in Chemistry and MSc in Analytical Chemistry from Ilam University, Ilam, Iran, in, respectively, 2006 and 2008. She also received her PhD in Analytical Chemistry from Yazd University, Yazd, Iran, in 2016. 